effect. Essentially, the start door procedure employed in the later trials consisted of opening the door immediately after placing $S$ in the start box (SB). Under these conditions, $\mathrm{S}$ - speeds for Group 1-8 showed a marked decline from the level obtained when S was detained in SB for $3 \mathrm{sec}$. Assuming, with Capaldi (1967), that large and small rewards occasion specific stimulus aftereffects which are reinstated by apparatus cues, these stimuli would serve as cues in SB for the reward to be received on any trial. In the postshift period, runway measures were taken as soon as $S$ was exposed to these cues, a procedure which is more sensitive to differential response tendencies to $S-$ as compared with S+ (Ludvigson \& Gay, 1967).

\section{REFERENCES}

AMSEL, A. Frustrative nonreward in partia reinforcement and discrimination learning: Some recent history and a theoretical extension. Psychological Review, 1962, 69, 306-328.

CAPALDI, E. J. A sequential hypothesis of instrumental learning. In K. W. Spence and J. T Spence (Eds.), The psychology of learning and motivation. Vol. 1. New York: Academic Press, 1967.
DALY, J. B. Excitatory and inhibitory effects of complete and incomplete reward reduction in the double runway. Joumal of Experimental Psychology, 1968, 76, 430-438.

DUNHAM, P. J. Contrasted conditions of reinforcement: A selective critique. Psychological Bulletin, 1968, 69, 295-315.

LUDVIGSON, H. W., \& GAY, S. E. Differential reward conditioning: $S$ - contrast as a function of the magnitude of S+. Psychonomic Science, $1966,5,289-290$.

LUDVIGSON, H. W., \& GAY, R. A. An investigation of conditions determining contrast effects in differential reward conditioning. Journal of Experimental Psychology, 1967, 75, 37-92.

MacKINNON, J. R. Interactive effects of the two rewards in a differential magnitude of reward discrimination. Journal of Experimental Psychology, 1967, 75, 329-338.

McHOSE, J. H., \& LUDVIGSON, H. W. Role of reward magnitude and incomplete reduction of reward magnitude in the frustration effect. Journal of Experimental Psychology, 1965, 70, 490-495.

MCHOSE, J. H., MEYER, P. A., \& MAXWELL, F. $R$. Frustration effects as a function of training magnitude in a within-S design. Psychonomic Science, $1969,14,137-138$ NOTES

1. Supported by Research Grant MH-10340 and Training Grant MH 07817 from the United States Public Health Service.

2. Now at the University of South Dakota, Vermillion, S. Dak.

\title{
A demonstration of overshadowing in operant conditioning',2
}

\section{G. MILES, ${ }^{2}$ McMaster University, Hamilton, Ontario, Canada}

Seventeen pigeons were trained on a go/no-go discrimination with tone and light as positive trial stimuli. Negative trials for three different groups were: (a) light and noise, (b) tone and a dark key, and (c) a dark key and noise. Stimulus control tests in extinction consisted of presenting four different brightness levels of the key-light presented with and without tone. The results showed that, for the pigeon, light overshadows tone.

When two stimulus features are presented to an animal in a compound they may not both become strongly associated with a reinforced response made in the presence of that compound. In the extreme case, only one of the stimuli may become associated to the complete exclusion of the other. Pavlov (1927) demonstrated this phenomenon using dogs as Ss. His procedure was to condition responding in the presence of two stimuli and then present the two elements alone. When responding to one element was equal to the response elicited by the compound and the second element showed little or no evidence of conditioning, the strongly conditioned element was said to have "overshadowed" the element which did not condition. Independent evidence indicated that had the weaker element been presented alone, conditioning would have taken place.

There is some evidence for overshadowing in operant discrimination learning. One demonstration is an experiment by Newman \& Baron (1965). They found that pigeons trained to peck at a white line on a green background as $\mathrm{S}+$ and a red key as $\mathrm{S}$ showed no control by line tilt. When $S-$ was a green key good control by line tilt occurred. The difference in color overshadowed line tilt. The present experiment used a discriminated trial procedure (Jenkins, 1962) and measured control by both features after training. SUBJECTS AND APPARATUS

The Ss were 5- to 6-year-old male White King pigeons which were run at approximately $80 \%$ of their free-feeding weight.

The basic apparatus was three automatic key-pecking boxes with response keys which could be backlighted. The experiment was controlled by five channel tape readers, relay switching circuits, and timers. Total counts of various events were recorded on impulse counters.

Auditory stimuli were either a tone at 1000 cycles or a broad-band white noise. When tone was switched on noise was switched off. Either tone or noise was on throughout the experimental sessions. The intensity of both tone and noise was maintained at $80-\mathrm{dB}$ sound pressure. Visual stimuli were different brightness levels of the key which were procured by varying the voltage across the stimulus lamp. These were designated L1(24.3 V), L2(21.9 V), L4(19.1 V), L5(16.3 V). A dark key (0 V) was designated $\mathrm{D}$.

\section{PROCEDURE}

Subjects were initially shaped to peck a lighted key with the tone on, and were then given four sessions of pretraining. Each session consisted of 40 trials separated by an intertrial interval (a dark key and white noise were present) ranging from 35 to $90 \mathrm{sec}$. Throughout all experimental sessions the houselight was on. Trials began with the illumination of the response key and the onset of the tone. If S completed the response requirement (raised from one to four during the first five trials of pretraining), the trial terminated with $4 \mathrm{sec}$ access to grain. Otherwise the trial ended, with reinforcement, after $8 \mathrm{sec}$. During the 12 discrimination training sessions which followed, both positive and negative trials were presented. Forty reinforced, or St, trials were randomly intermixed with $\mathbf{4 0}$ nonreinforced, or $\mathbf{S}-$, trials. For all Ss, $\mathbf{S +}$ consisted of light plus tone, designated TL1. There were three different experimental groups differing only with respect to the stimuli on negative trials. For Group TL1-L1 $(\mathrm{N}=5)$ noise and L1 were presented. In Group TL1-TD $(\mathrm{N}=6)$ it was tone and a dark key. For Group TL1-D $(N=6) S-$ was noise and a dark key.

Tests for stimulus control were given after discrimination training. Four test sessions were run on successive days. Tests were made at four points along a generalization gradient based on decreasing intensities of the key-light; the four light levels designated $\mathrm{L} 1, \mathrm{~L} 2, \mathrm{~L} 4$, and $\mathrm{L} 5$ were presented. At each light level trials were presented with and without tone, yielding a total of eight different stimuli which were presented in 10 independent random orders making a total of 80 presentations in a session. Except for 

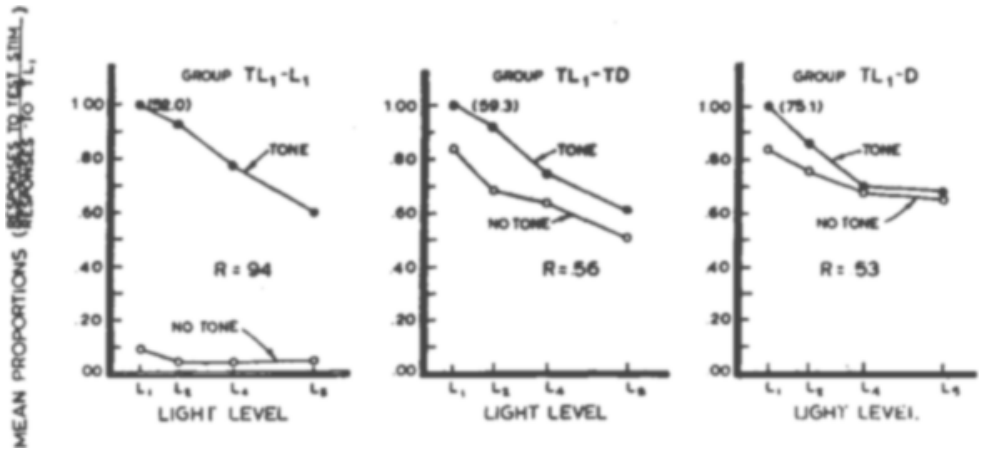

the absence of reinforcement, trials were programmed and terminated as in training. From these data an overall index of control by tone was calculated. The index, designated $R$, consists of the ratio of the number of responses on tone trials to the total number of responses.

\section{RESULTS AND DISCUSSION}

Pretraining and Training

By the fourth session of pretraining all Ss were completing response units on almost every St trial. During training the mean probability of completing a response unit on S+ trials was not less than .99 in any group, while the mean number of intertrial responses per session was not more than 1.4 in each group.

Mean total responses to $S-$, in 480 negative trials during training, was 1.5 for Group TL1-TD and 1.3 for Group TL1-D; no $S$ in either group completed a response unit on $S-$ trials. The results for Group TL1-L1 were in sharp contrast: Mean total number of responses on $S$ - trials during discrimination training was 852.4 . It is clear from the training results that the light feature is very much more prominent than the tone feature. It is also clear that the discrimination proceeds just as rapidly when positive trials are distinguished from negative trials only by brightness differences as when they are distinguished by both brightness differences and the presence of tone.

\section{Test for Stimulus Control}

The principal results of the stimulus control test are presented in Fig. $1 .^{3}$ For each group responding to each of the test stimuli summed over the four sessions is presented as a proportion of responding during test to TL1, the positive stimulus during training. The mean $R$ index (proportion of total test responses made in the presence of the tone) is also shown for each group. An analysis of variance was conducted on the $R$ index based on total responses to each stimulus over the four test sessions. The mean for the groups differed significantlly $(F=172.63, \quad d f=2 / 14$, $\mathrm{p}<.001$ ). Clearly the greatest part of the variance is accounted for by the high control by tone shown by Group TL1-L1; the lowest value of $R$ in this was .88 whereas the highest value of $R$ in the other two groups was .61. An individual comparison of the results for Group TL1-TD and Group TL1-D showed the means for these groups $(R=.56$ and $R=.53$, respectively) to be not significantly different $(p>.10)$. However, the pooled Rs for these two groups were significantly different from a value of .50 expected on the hypothesis of no effect of tone on responding. The results of other experiments (Miles, 1965), where certain groups were trained without tone and tested as in the present experiment, make it quite clear that control by tone in the present case depended on the presence of tone during training. Control by the tone does not arise through some unconditioned facilitating effect on responding in extinction.

The summed data for the four sessions of testing was subjected to an analysis of variance. Mean total responding, which is shown in brackets in Fig. 1, did not vary
Fig. 1. Mean responses to tone and no-tone trials relative to responses to TL1 at each of four test light levels.

significantly between groups. The effect of tone was significant ( $F=67.51$, df $=1 / 14$, $\mathrm{p}<.001)$ which confirms the results of the analysis base; on $\mathbf{R}$. The slope of the gradient over test light levels was verified by an $F=29.63(\mathrm{df}=3 / 42, \mathrm{p}<.001)$. Of critical importance in this analysis was the significant interaction between tone vs no-tone on test and $S$ - in training ( $F=26.34, \mathrm{df}=2 / 14, \mathrm{p}<.01$ ). This result also confirms the analysis based on $R$. It can be concluded, therefore, that in Group TL1-D, where the discrimination could be formed on the basis of tone or light, tone acquired significantly less control than in Group TL1-L1 where tone alone was relevant: therefore, this experiment demonstrates clearly that, for the pigeon, white light overshadows a simultaneously presented tone.

\section{REFERENCES}

JENKINS, H. M. Resistance to extinction when partial reinforcement is followed by regular reinforcement. Journal of Experimental Psychology, 1962, 64, 441-450.

MILES, C. G. Acquisition of control by the features of a compound stimulus in discrimina tive operant conditioning. Unpublished doctoral dissertation, McMaster University, 1965.

NEWMAN, F. L., \& BARON, M. R. Stimulus generalization along the dimension of angularity. Joumal of Comparative \& Physiological Psychology, 1965, 60, 59-63.

PAVLOV, I. P. Conditioned reflexes. Translated by G. V.Anrep. New York: Dover, 1927.

\section{NOTES}

1. From a dissertation submitted in partial fulfillment of the requirements for the $\mathrm{PhD}$ degree, McMaster University, 1965. The author wishes to record his appreciation for the encouragement and help given by H. M. Jenkins who supervised this work. Preparation of this manuscript was financed by National Research Council Contract APA-259 to N. J. Mackintosh.

2. Now at Delhousie University.

3. The spacing of the light levels in this figure was achieved by a fractionation procedure using human Ss. This spacing is used simply as an aid in visualixing the results and plays no part in their interpretation.

\section{ERRATUM}

Lattal, K. A., \& Cooper, A. M. Escape from punishment by ommission of responding. Psychonomic Science, 1969, 15 (5), 263-264.-On page 263 the sentence beginning in Column 1, line 28 , should read as follows: The delivery of punishment following a key peck response during the last $2 \mathrm{~min}$ of the warning stimulus resulted in a cessation of responding that often continued until the warning stimulus, and associated punishment contingency, terminated. 